\title{
In silico polymorphism analysis for the development of simple sequence repeat and transposon markers and construction of linkage map in cultivated peanut
}

Kenta Shirasawa ${ }^{1 *}$, Padmalatha Koilkonda ${ }^{1}$, Koh Aoki $^{1,6}$, Hideki Hirakawa ${ }^{1}$, Satoshi Tabata ${ }^{1}$, Manabu Watanabe ${ }^{2}$, Makoto Hasegawa ${ }^{2}$, Hiroyuki Kiyoshima², Shigeru Suzuki ${ }^{2}$, Chikara Kuwata², Yoshiki Naito ${ }^{3}$, Tsutomu Kuboyama ${ }^{4}$, Akihiro Nakaya ${ }^{5}$, Shigemi Sasamoto ${ }^{1}$, Akiko Watanabe ${ }^{1}$, Midori Kato ${ }^{1}$, Kumiko Kawashima', Yoshie Kishida ${ }^{1}$, Mitsuyo Kohara ${ }^{1}$, Atsushi Kurabayashi ${ }^{1}$, Chika Takahashi ${ }^{1}$, Hisano Tsuruoka ${ }^{1}$, Tsuyuko Wada ${ }^{1}$ and Sachiko Isobe ${ }^{1}$

\begin{abstract}
Background: Peanut (Arachis hypogaea) is an autogamous allotetraploid legume $(2 n=4 x=40)$ that is widely cultivated as a food and oil crop. More than 6,000 DNA markers have been developed in Arachis spp., but highdensity linkage maps useful for genetics, genomics, and breeding have not been constructed due to extremely low genetic diversity. Polymorphic marker loci are useful for the construction of such high-density linkage maps. The present study used in silico analysis to develop simple sequence repeat-based and transposon-based markers.

Results: The use of in silico analysis increased the efficiency of polymorphic marker development by more than 3fold. In total, 926 (34.2\%) of 2,702 markers showed polymorphisms between parental lines of the mapping population. Linkage analysis of the 926 markers along with 253 polymorphic markers selected from 4,449 published markers generated 21 linkage groups covering 2,166.4 cM with 1,114 loci. Based on the map thus produced, 23 quantitative trait loci (QTLs) for 15 agronomical traits were detected. Another linkage map with 326 loci was also constructed and revealed a relationship between the genotypes of the FAD2 genes and the ratio of oleic/linoleic acid in peanut seed.

Conclusions: In silico analysis of polymorphisms increased the efficiency of polymorphic marker development, and contributed to the construction of high-density linkage maps in cultivated peanut. The resultant maps were applicable to QTL analysis. Marker subsets and linkage maps developed in this study should be useful for genetics, genomics, and breeding in Arachis. The data are available at the Kazusa DNA Marker Database (http://marker.kazusa.or.jp).
\end{abstract}

Keywords: DNA marker, Genetic linkage map, Peanut (Arachis hypogaea), QTL analysis, Ratio of oleic/linoleic acid (O/L ratio)

\footnotetext{
* Correspondence: shirasaw@kazusa.or.jp

${ }^{1}$ Kazusa DNA Research Institute, 2-6-7 Kazusa-Kamatari, Kisarazu, Chiba 292-0818, Japan

Full list of author information is available at the end of the article
} 


\section{Background}

Peanut (Arachis hypogaea) is an autogamous allotetraploid legume $(2 n=4 x=40)$ composed of $A$ and $B$ genomes that are derived from two diploids, most likely $A$. duranensis (A genome) and $A$. ipaënsis (B genome). On the basis of branching habit, the presence/absence of flowers on the main stem, alternate vs. sequential branching, fruit and seed traits, and maturity, A. hypogaea has been categorized into two subspecies: hypogaea and fastigiata; six botanical varieties: hypogaea, hirsuta, fastigiata, vulgaris, aequatoriana, and peruviana; and four agronomic types: Virginia, Spanish, Valencia, and Southeast-runner $[1,2]$. As the nuclear DNA content in peanut is calculated to be $5.914 \mathrm{pg} /$ $2 \mathrm{C}$ [3], the genome size is estimated to be approximately $2.8 \mathrm{~Gb}$ based on an assumption that $1 \mathrm{pg}$ of DNA is equivalent to $980 \mathrm{Mb}$ [4]. Because of its allotetraploidy and large genome size, genomic study in the peanut has lagged far behind that of other legumes, such as Lotus japonicus [5], Glycine max [6], Medicago truncatula [7], and Cajanus cajan [8]. In addition, low genetic diversity within the species has inhibited the advance of genetic linkage map construction. In autogamous species, the genetic diversity of polyploids is generally more narrow than that of their diploid progenitors due to bottleneck effects, and this results in few alleles having been transferred from diploid progenitors to their polyploid descendents [9]. Moreover, genetic diversity is affected by the history of polyploidization. Tetraploid peanut is thought to have arisen approximately 3,500 years ago [10], and its short history has been considered a source of lower levels of polymorphism compared with diploid Arachis species [11].

At present, more than 6,000 DNA markers have been developed in Arachis spp. [12], e.g., restriction fragment length polymorphism $[13,14]$ and simple sequence repeats (SSRs) [11,15-21]. Linkage maps were constructed in wild diploids [14,19,22,23], cultivated species [21,24-26], and artificial amphidiploids derived from wild diploids [13,27]. Integrated maps based on cultivated peanuts were also constructed [28-31]. However, the peanut linkage map has not yet covered all of the chromosomes of the haploid genome $(n=20)$. Although extremely low genetic diversity has inhibited the construction of high-density genetic linkage maps in peanut, increasing the number of polymorphic markers is crucial for the saturation of linkage maps in peanut.

In general, SSR markers have been developed from randomly collected sequence data of complementary DNAs (cDNAs) [11,15], SSR-enriched genomic DNA libraries [16-20], and BAC-ends [21]. Primers were designed based on flanking regions of identified SSRs of the obtained sequences, and then polymorphism of the targeted SSRs was investigated using gel or capillary electrophoresis of DNA amplified by PCR. However, since the degree of polymorphism of the markers depends on the genetic diversity of the germplasm, experimental analysis requires considerable cost, time, and labor to develop a large number of polymorphic markers in species having low genetic diversity. Therefore, this strategy is not effective for the large-scale development of polymorphic DNA markers in closely-related lines. For the development of single nucleotide polymorphism (SNP) markers, on the other hand, in silico polymorphism analysis, i.e., comparison of genomic or cDNA sequences derived from more than two lines, is often performed before synthesizing primers of DNA markers for lab validation. To our knowledge, this approach has been limited, e.g., polySSR [32] and SSRpoly [33]. However, we consider that in silico polymorphism analysis prior to primer synthesis is also effective for SSR and other types of DNA marker development.

Recently, we have developed a total of 504 AhMITE1 transposon markers in peanut [34]. The percentage of the transposon markers that were polymorphic between the two peanut lines was $22.0 \%$, which was higher than that of the SSR markers $[11,35]$. This result suggested that transposon markers, like SSR markers, represent potent, co-dominant, and PCR-based markers.

Peanut is widely cultivated in Asia, Africa, America, and Australia as a food and oil crop. Peanut breeding has achieved a rise in productivity by increasing the size and number of seeds, and by enhancing resistance to biotic and abiotic stresses [36]. Breeding has been mostly performed by conventional methods, e.g., a combination of crossing, phenotypic selections, and homogenization. In conventional breeding, large sizes of breeding populations are required, especially for the selection of recessive traits, because single gene mutations often do not confer phenotypic variation in peanut due to functional complementation by homoeologous genes. Thus, molecular breeding with marker-assisted selection has great promise and may lead to remarkable advances in peanut breeding. While quantitative trait locus (QTL) analysis is an effective method for identification of DNA markers linked to agronomically important traits, few QTL studies have been conducted due to the lack of high-density linkage maps in peanut $[25,28,30,31]$.

Because peanut is used as an oil crop, seed quality is also an important breeding objective. The major components of peanut oil are linoleic acid and oleic acid, consisting of $36-67 \%$ and $15-43 \%$ of total oil, respectively, in normal cultivars [37]. Whereas normal cultivars have a ratio of oleic to linoleic acid $(\mathrm{O} / \mathrm{L}$ ratio) of about $1: 4$, the ratio can reach as high as $1: 30$ or $1: 40$ in high- $\mathrm{O} / \mathrm{L}$ ratio cultivars [38]. Oleic acid is a monounsaturated fatty acid, whereas linoleic acid is a polyunsaturated fatty acid. Therefore oleic acid is less oxidized than linoleic acid, and it is considered that oleic acid is better for health and storage quality [39]. In high-O/L ratio plants, oleic 
acid is synthesized from stearic acid and is converted into linoleic acid by two fatty acid desaturases encoded by $S A D$ and FAD2 [40]. The selection of mutated alleles of $F A D 2$, which is associated with oleic-acid content in seeds [41-43], is a straightforward strategy to efficiently generate high-oleic acid crops. In peanut, $a h F A D 2 A$ and ahFAD $2 B$ have been identified on the A and $\mathrm{B}$ genomes, respectively, and the mutant alleles are reported to confer a high $\mathrm{O} / \mathrm{L}$ ratio [44-49].

In this study, we investigated whether in silico polymorphism analysis could increase the efficiency of development of polymorphic SSR and transposon markers. First, genomic sequences covering SSR and transposoninserted regions derived from two peanut lines were compared in silico to identify candidate polymorphic regions. Then, the candidate polymorphic regions were subjected to lab validation. High-density genetic linkage maps were constructed using the developed polymorphic markers along with published markers. The developed linkage maps demonstrated their applicability to molecular breeding through QTL mapping for agronomical traits and FAD2 gene mapping for the development of varieties with high $\mathrm{O} / \mathrm{L}$ ratios.

\section{Methods}

\section{Plant materials and DNA extraction}

Two $F_{2}$ mapping populations, i.e., SKF2 and NYF2, were used for the construction of linkage maps. The SKF2 $(n=94)$ was generated from a cross between two lines belonging to different agronomic and morphological types, i.e., a Virginia type, 'Satonoka', and a Spanish type, 'Kintoki'. The SKF2 population is expected to generate a larger number of polymorphic markers for construction of a high-density linkage map. It has also been used for the identification of 15 agronomic trait loci. The NYF2 $(\mathrm{n}=186)$ is a breeding population derived from a cross between a Virginia type, 'YI-0311', which is also considered as a Southeast-runner type, and another Virginia type, 'Nakateyutaka'. The former is a breeding line showing a high $\mathrm{O} / \mathrm{L}$ ratio in seeds, and the latter is a leading cultivar in Japan with a normal $\mathrm{O} / \mathrm{L}$ ratio. This mapping population was used for the identification of linkages between genotypes of $F A D 2$ genes and $\mathrm{O} / \mathrm{L}$ ratio in seeds. Genomic DNA from each line was extracted using the DNeasy Plant Mini kit (Qiagen, Germany).

\section{Development of SSR markers by in silico polymorphism analysis}

To develop SSR markers, two SSR-enriched genomic libraries were constructed, as described by Nunome et al. [50]. While the first library was generated from a single line, 'Satonoka', the second library was developed using two lines, 'Satonoka' and 'Kintoki', for in silico polymorphism analysis. Both libraries were constructed with biotinylated oligo probes of $(A C)_{12}$ and $(C T)_{12}$. Sequencing analysis of all libraries and primer design for the first library were performed as described by Sraphet et al. [51]. For the second library, primers were designed based only on flanking sequences of polymorphic SSRs between 'Satonoka' and 'Kintoki', identified by in silico analysis as described below. The SSR motifs in the sequences were identified by the Fuzznuc tool from EMBOSS, version 6.1.0 [52], and the sequences with SSR motifs were assembled by the CAP3 program with parameters set to require $95 \%$ identify to be considered overlapping (-p 95) [53]. Of the obtained assemblies, contigs comprising sequences with different lengths of the same SSR motifs (different numbers of the same repeated sequence) between two lines were selected as polymorphic SSR candidates for primer design. All of the designed genomic SSR markers were designated as AHGS ( $\underline{\text { Ara- }}$

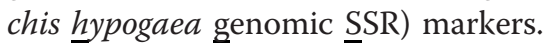

\section{Development of transposon markers through in silico polymorphism analysis}

Shirasawa et al. [34] reported that insertion sites in the peanut genome for the transposon AhMITE1 differ among cultivars. They also demonstrated that the insertional polymorphisms of transposon elements can be used as DNA markers by developing 504 polymorphic markers derived from transposon-enriched genomic libraries. To develop additional transposon markers, transposon-enriched genomic libraries were constructed from 'Satonoka' and 'Kintoki', and sequences were obtained as previously described [34]. The individual sequences were assembled using the CAP3 program with default parameters [53]. Contigs and singlets having AhMITE1 sequences only on one cultivar (either 'Satonoka' or 'Kintoki', but not both) were selected as candidate polymorphic sequences. Using the PRIMER3 program [54], primers were designed on both flanking sequences of AhMITE1, or on one of the flanking sequences and an internal sequence of AhMITE1 in cases lacking either flanking sequence.

Additionally, the flanking sequences of the AhMITE1 transposons were cloned using inverse PCR. Genomic DNA fragments digested by MboI, MseI, or XspI were self-ligated using T4 DNA ligase (Promega, USA) and used as PCR templates. Ten microliters of PCR mixture, composed of $0.04 \mathrm{ng} / \mu \mathrm{l}$ template DNA, $0.5 \mathrm{pmol} / \mu \mathrm{l} \mathrm{pri}-$ mer pairs (Additional file 1), 1X PCR buffer (Bioline, UK), $0.2 \mathrm{mM}$ dNTPs, $5 \mathrm{mM} \mathrm{MgCl}$, and $0.25 \mathrm{U}$ BioTaq DNA polymerase (Bioline), was used. The thermal cycling conditions were as follows: a 1 min initial denaturation at $94{ }^{\circ} \mathrm{C}$; 35 cycles of $30 \mathrm{~s}$ denaturation at $94{ }^{\circ} \mathrm{C}$, $30 \mathrm{~s}$ of annealing at $60^{\circ} \mathrm{C}$, and a $90 \mathrm{~s}$ extension at $72{ }^{\circ} \mathrm{C}$; and a $3 \mathrm{~min}$ final extension at $72{ }^{\circ} \mathrm{C}$. The amplified DNAs were ligated into pGEM-T ${ }^{\circledR}$ Easy plasmids 
(Promega). Plasmids were introduced into Escherichia coli ElectroTen-blue (Stratagene, USA) by electroporation. Following the amplification of DNA inserts with the Illustra TempliPhi DNA Amplification Kit (GE Life Sciences, USA), nucleotide sequences were determined using the BigDye Terminator Kit (Applied Biosystems, USA) and an ABI 3730xl DNA sequencer (Applied Biosystems).

The transposon markers were designated as AhTE (Arachis hypogaea transposable element), as described in Shirasawa et al. [34].

\section{SSR markers derived from BAC-end sequences}

BAC libraries for A. duranensis (AA) and A. ipaënsis (BB) have been constructed by Guimarães et al. [55]. Dr. Bertioli, University of Brasilia, Brazil, and his colleagues determined the end sequences of the BAC clones and designed primers on flanking regions of identified SSRs (Bertioli, personal communication). These BAC-end derived SSR markers kindly provided by Dr. Bertioli were also subjected to polymorphism analysis (Additional file 2).

\section{Polymorphism analysis of the DNA markers}

In addition to the AHGS and AhTE markers developed in this study, a total of 4,449 previously published markers $[11,15-20,34]$ were used for the polymorphism analysis (Additional file 2). PCR reactions were performed using $0.5 \mathrm{ng}$ genomic DNA in each $5 \mu \mathrm{l}$ reaction. In addition to template DNA, PCR reaction mixtures contained 1X PCR buffer (Bioline), $3 \mathrm{mM} \mathrm{MgCl}_{2}, 0.04 \mathrm{U}$ BIOTAQ $^{\mathrm{TM}}$ DNA polymerase (Bioline), $0.2 \mathrm{mM}$ dNTPs, and $0.8 \mu \mathrm{M}$ of each primer. The thermal cycling conditions were as follows: $1 \mathrm{~min}$ denaturation at $94{ }^{\circ} \mathrm{C}$; 35 cycles of $30 \mathrm{~s}$ denaturation at $94{ }^{\circ} \mathrm{C}, 30 \mathrm{~s}$ of annealing at $60{ }^{\circ} \mathrm{C}$, and a $1 \mathrm{~min}$ extension at $72{ }^{\circ} \mathrm{C}$; and a final $3 \mathrm{~min}$ extension at $72{ }^{\circ} \mathrm{C}$. The PCR products were separated by $10 \%$ polyacrylamide gel electrophoresis in $1 \mathrm{X}$ TBE buffer according to the standard protocol, or with a fluorescent fragment analyzer, ABI 3730xl (Applied Biosystems, USA). In the latter case, the data were analyzed using GeneMapper software (Applied Biosystems).

The previously reported SNP in ahFAD2A and transposon insertional polymorphism in $a h F A D 2 B$ were also investigated to check the existence of polymorphisms in the NYF2 population $[49,56,57]$. The SNP was genotyped by the TaqMan assay with primer pairs (5'CCCTTCACTCTTGTCTATTAGTTCCTTAT-3' and 5'TGATACCTTTGATTTTGGTTTTGG-3') and TaqMan probes (FAM-labeled 5'-CCTCGACCGCAACG-3' for mutant allele and VIC-labeled 5'-CCTCGACCGCGACG-3' for the wild-type allele) on the 7900HT Fast Real-Time PCR System (Applied Biosystems). The TaqMan assay was performed according to the protocol of the TaqMan Genotyping Master Mix (Applied Biosystems). Transposon insertional polymorphisms were detected on $2 \%$ agarose gel as a difference in mobility of the DNA fragments that had been amplified by PCR with primers bF19: 5'-CAGAACCATTAGCTTTG-3' and R1: 5'-CTCTGACTATGCATCAG-3' [49]. PCR and electrophoresis were performed as described above.

\section{Construction of linkage maps}

Linkage analysis was performed on segregated genotypic data from the two mapping populations using JoinMap ${ }^{\circledR}$ version 4 [58]. The marker loci were roughly classified using the JoinMap ${ }^{\circledR}$ grouping module with logarithm of odds (LOD) scores of 4.0-10.0. Marker order and genetic distance were calculated using a regression mapping algorithm with the following parameters: Haldane's mapping function, recombination frequency $\leq 0.30$, and LOD score $\geq 2.0$. The graphical linkage maps were drawn with the MapChart program [59].

\section{Phenotyping and QTL analysis}

A total of 15 morphological traits of the SKF2 population were investigated in the Peanut Plant Breeding Field of the Chiba Prefectural Agriculture and Forestry Research Center, Japan ( $\left.35^{\circ} 37^{\prime} 54^{\prime \prime} \mathrm{N}, 140^{\circ} 19^{\prime} 02^{\prime \prime} \mathrm{E}\right)$. The seeds were sown in May, 2005 with $66 \mathrm{~cm}$ and $20 \mathrm{~cm}$ inter- and intra-row spacing, respectively. The flowering date for each plant was determined based on the opening of the first flower. Numbers and angles of branches, lengths of main stems and the longest branches, and fresh weights of the whole plant were measured at the harvesting stage. After drying of harvested pods under natural conditions for two weeks, the length, thickness, width, and weight of the matured pods were measured. In addition, constrictions on the pods were scored from 1 (deep) to 5 (shallow), and the shapes of the tips of the pods were also scored from 1 (round) to 5 (sharp). After that, numbers of seeds per plant and mean weights of single seeds were investigated. Colors of seed coats were classified as orange-yellow (2.5Y 8/6) or brown-red (2.5R 4/10), based on the Munsell color system.

To investigate the fatty acid content of the seeds, the $32 F_{1}$ parents of the NYF2 mapping population were planted in the Peanut Plant Breeding Field of the Chiba Prefectural Agriculture and Forestry Research Center in May, 2008 with $66 \mathrm{~cm}$ and $30 \mathrm{~cm}$ inter- and intra-row spacing, respectively. The $F_{2}$ seeds were harvested in October and dried for one month in an open-air condition in their pods. One quarter of each of the dried seeds was cut off, and then $25 \mathrm{mg}$ of the seeds was homogenized using TissueLyzer (Qiagen) with $400 \mu \mathrm{l}$ of $100 \%(\mathrm{v} / \mathrm{v})$ methanol. The homogenate was incubated at $70{ }^{\circ} \mathrm{C}$ for $15 \mathrm{~min}$ with $1,100 \mu \mathrm{l}$ of $91 \%(\mathrm{v} / \mathrm{v})$ methanol and then centrifuged at $15,000 \mathrm{rpm}$ for $5 \mathrm{~min}$. The supernatant was transferred 
to a glass tube. The pellet was resuspended in $750 \mu \mathrm{l}$ of chloroform with $2 \mathrm{mg} / \mathrm{ml}$ nonadecanoic acid methyl ester (Sigma-Aldrich, USA), and the chloroform (resuspended pellet) layer was mixed with the supernatant layer. After washing the mixture with water, $900 \mu \mathrm{l}$ chloroform and $1 \mathrm{ml}$ of $3 \%(\mathrm{v} / \mathrm{v})$ sulfuric acid in methanol were added to the chloroform layer, followed by washing with water. Then, $10 \mu \mathrm{l}$ of the chloroform layer was dried with $\mathrm{N}_{2}$ gas, $70 \mu \mathrm{l}$ n-heptane, $10 \mu \mathrm{l}$ pyridine, and $10 \mu \mathrm{l} \mathrm{N}$-methyl-N-(trimethylsilyl)trifluoroacetamide (Sigma-Aldrich). Fatty acid quantification was performed using gas chromatography time-of-flight mass spectrometry (GC-TOF-MS) with a 6890 N Network GC System (Agilent Technologies, USA) equipped with a column DB17MS (length, $30 \mathrm{~m}$; ID, $0.25 \mathrm{~mm}$; film, $0.25 \mu \mathrm{m}$ ) (J\&W Scientific, USA), coupled to Pegasus3 (Leco ${ }^{\circledR}$, USA) with the following settings: inlet temperature, $250{ }^{\circ} \mathrm{C}$; oven temperature, $70{ }^{\circ} \mathrm{C}$ for $5 \mathrm{~min}$, increasing by $15^{\circ} \mathrm{C} / \mathrm{min}$, and holding at $310{ }^{\circ} \mathrm{C}$ for $5 \mathrm{~min}$; transfer tube temperature, $200{ }^{\circ} \mathrm{C}$; and ion source temperature, $250{ }^{\circ} \mathrm{C}$. Acquisition and analysis of mass spectral data were performed using the ChromaTOFTM version 2.32 optimized for Pegasus $\left(\right.$ Leco $\left.^{\circledR}\right)$. Concentrations of oleic acid, linoleic acid, palmitic acid, and stearic acid were estimated from calibration curves created using pure samples of each compound.

The phenotypic data regarding morphological traits of the SKF2 population were subjected to composite interval mapping by the Windows QTL Cartographer program [60]. The thresholds of LOD for each QTL were determined by 1,000 permutation tests. Since two genes, ahFAD2A and $a h F A D 2 B$, were reported to control the $\mathrm{O} / \mathrm{L}$ ratio in seeds with epistatic interactions, QTL analysis of the NYF2 population was conducted with Genotype Matrix Mapping (GMM) software with the following parameters: Max Length of Locus Combination =2; Min Number of Corresponding Samples=1; Search Range $=$ auto [61].

\section{Results}

\section{Design of polymorphic genomic SSR markers}

In the first library, a total of 11,673 genomic clones were sequenced. After removing redundant sequences, 2,661 primer pairs were designed to amplify the flanking regions of SSRs [DNA Data Bank of Japan (DDBJ): DH961577DH964237] and designated as AHGS markers [62] (Additional file 3). Out of the 2,661 AHGS markers, 334 were screened for polymorphism compared with the four parental lines of the mapping populations using a fluorescent fragment analyzer. According to the results, 42 (12.6\%) and 6 (1.8\%) markers showed polymorphism between 'Satonoka' and 'Kintoki' and between 'Nakateyutaka' and 'YI-0311', respectively.

The second pair of genomic SSR libraries for in silico polymorphism analysis was constructed from 'Satonoka' and 'Kintoki', and a total of 7,872 and 8,208 clones were sequenced, respectively. After trimming vector, linker, and low-quality sequences, sequences with SSR motifs were assembled into 10,742 unique sequences consisting of 2,952 and 7,788 SSR-containing contigs and singlets, respectively. In the comparative analysis of the lengths of SSR motifs on each sequence, for 126 (4.3\%) of the 2,952 contigs, the SSR repeats differed in length between 'Satonoka' and 'Kintoki', while 287 contigs $(9.7 \%)$ had identical-length SSR repeats between the two lines. The remaining 2,539 contigs (86.0\%), as well as 7,788 singlets, were composed of fragments derived from either line. After eliminating sequences that were identical to those from the first library, 126 primer pairs were designed to amplify polymorphic sequences, 287 were designed to amplify non-polymorphic sequences, and 3,606 additional, untested primer pairs were designed [63; DDBJ: DH964238-DH968256] (Additional file 3). Screening for polymorphism was performed using a fluorescent fragment analyzer with the parental lines of the mapping populations, the SKF2 and the NYF2, with 1,833 primer pairs consisting of 74,121 , and 1,638 primer pairs randomly selected from polymorphic, non-polymorphic, and untested SSR candidate data, respectively. A total of 582 of the tested 1,833 markers (31.8\%) showed polymorphisms between 'Satonoka' and 'Kintoki', including 29 of the 74 candidate polymorphic (39.2\%), 25 of the 121 candidate non-polymorphic (20.7\%), and 528 of the 1,638 untested (32.2\%) markers. Of the candidate polymorphic markers, the remaining $45(60.8 \%)$ were monomorphic between the parental lines. Between 'Nakateyutaka' and 'YI-0311', 11 candidate polymorphic (14.9\%), 10 candidate non-polymorphic $(8.3 \%)$, and 162 candidate probable polymorphic (9.9\%) markers showed polymorphism. As results of the polymorphism screenings with a total of 2167 genomic SSR markers, 624 (28.8\%) and 189 (8.7\%) showed polymorphisms between 'Satonoka' and 'Kintoki' and between 'Nakateyutaka' and 'YI-0311', respectively (Table 1).

A total of 6,680 AHGS markers were designed from the first and second SSR-enriched genomic libraries. Out of these markers, the poly $(\mathrm{CT})_{\mathrm{n}}$ motif was the most abundant (2,390: $35.8 \%)$, followed by poly $(\mathrm{AC})_{\mathrm{n}}(1,496: 22.4 \%)$, due to the usage of biotinylated oligo probes of poly $(\mathrm{AC})_{12}$ and poly $(\mathrm{CT})_{12}$ in the construction of the libraries (Additional file 4). The frequencies of the other di-, tri-, and tetra-nucleotide repeat motifs were $13.1 \%, 5.6 \%$, and $23.1 \%$, respectively. The distributions of the SSR motifs found in the two libraries were not different. Between 'Satonoka' and 'Kintoki', the polymorphic ratio of the poly $(\mathrm{CT})_{\mathrm{n}}$ motif, $40.4 \%$ (498/ $1,232)$, was higher than that of the poly $(\mathrm{AC})_{\mathrm{n}}$ motifs, $14.2 \%$ (88/620) (Additional file 4).

Design and polymorphism analysis of transposon markers As with the AHGS marker development, transposon markers named AhTE were developed via in silico 
Table 1 Polymorphic ratio of the investigated markers

\begin{tabular}{|c|c|c|c|c|c|c|c|}
\hline & $\begin{array}{l}\text { Marker } \\
\text { types }\end{array}$ & $\begin{array}{l}\text { No. of } \\
\text { tested } \\
\text { markers }\end{array}$ & $\begin{array}{l}\text { No. of } \\
\text { polymorphic } \\
\text { markers } \\
\text { between } \\
\text { 'Satonoka' } \\
\text { and 'Kintoki' }\end{array}$ & $\%$ & $\begin{array}{l}\text { No. of } \\
\text { polymorphic } \\
\text { markers } \\
\text { between } \\
\text { 'Nakateyutaka' } \\
\text { and 'YI-0311' }\end{array}$ & $\%$ & References \\
\hline \multicolumn{8}{|c|}{ DNA markers developed in this study } \\
\hline & $\begin{array}{l}\text { Genomic } \\
\text { SSRs }\end{array}$ & 2167 & 624 & 28.8 & 189 & 8.7 & This study \\
\hline & Transposons & 535 & 302 & 56.4 & 67 & 12.5 & This study \\
\hline \multicolumn{8}{|c|}{ DNA markers derived from other studies } \\
\hline & $\begin{array}{l}\text { Genomic } \\
\text { SSRs }\end{array}$ & 418 & 87 & 20.8 & 18 & 4.3 & [16-20] \\
\hline & EST-SSRS & 3375 & 50 & 1.5 & 9 & 0.3 & {$[11,15]$} \\
\hline & BAC-end SSRs & 152 & 25 & 16.4 & 6 & 3.9 & Bertioli, pers. comm. \\
\hline & Transposons & 504 & 91 & 18.1 & 49 & 9.7 & [34] \\
\hline Total & & 7151 & 1179 & 16.5 & 338 & 4.7 & \\
\hline
\end{tabular}

polymorphism analysis. A total of 13,248 and 12,351 clones derived from AhMITE1-enriched genomic libraries of 'Satonoka' and 'Kintoki', respectively, were sequenced. Of the total 25,599 sequences, 16,639 were identified as including AhMITE1 sequences in the fragments. These were then assembled into 1,198 contigs. Cultivar-specific transposon insertions were identified in 511 out of the 1,198 contigs. In addition, 24 additional insertion sites were found from the libraries derived from the inverse PCR analysis. In total, 535 primer pairs were designed based on the flanking regions of identified AhMITE1s [63; DDBJ: DH968257-DH968767] (Additional file 5). When polymorphism analysis was performed using these 535 primer pairs with the four parental lines of the mapping population, a total of 302 (56.4\%) and 67 (12.5\%) markers exhibited polymorphism between 'Satonoka' and 'Kintoki', and between 'Nakateyutaka' and 'YI-0311', respectively (Table 1).

\section{Polymorphism analysis of the previously published marker loci}

A total of 4,449 markers derived from other studies, including 418 genomic SSRs [16-20], 3,375 EST-SSRs [11,15], 152 BAC-end SSRs (Bertioli, personal communication), and 504 transposon markers [34], were used for polymorphism analysis between the four mapping parents (Additional file 2). Out of the 4,449 markers, 253 (5.7\%), including 87 genomic SSRs (20.8\%), 50 EST-SSRs (1.5\%), 25 BAC-end SSRs (16.4\%), and 91 transposon markers (18.1\%), were selected as polymorphic markers between 'Satonoka' and 'Kintoki' (Table 1). Between 'Nakateyutaka' and 'YI-0311', 18 genomic SSRs (4.3\%), 9 EST-SSRs (0.3\%), 6 BAC-end SSRs (3.9\%), and 49 transposon markers $(9.7 \%)$ showed polymorphism (Table 1 ).

\section{Construction of the SKF2 genetic linkage map}

A total of 1,179 of the 7,151 (16.5\%) tested markers showed polymorphism between 'Satonoka' and 'Kintoki'. Nineteen, three, and one markers identified doubled, tripled, and quadrupled polymorphic loci, respectively, while 1,156 markers generated single polymorphic loci. Consequently, 1,207 segregating loci were generated from the 1,179 markers. A total of 1,114 of the 1,207 segregated loci (92.3\%) were mapped onto 21 linkage groups (LGs), resulting in the SKF2 genetic linkage map. The length of the genetic linkage map was 2,166.4 cM, with distances ranging from $44.1 \mathrm{cM}$ to $199.8 \mathrm{cM}$ (Table 2, Figure 1, Additional file 6). Of the 1,114 loci, 949 were generated from markers developed in this study and in Shirasawa et al. [34].

The LGs were named according to the consensus numbers of the previously reported maps by comparison of the mapping position of the 122 commonly mapped markers [19,22,23,25,27,28,30] (Figure 1, Additional file 7). Eight homoeologous pairs of linkage groups (HGs) were identified, i.e., 1, 3, 4, 5, 6, 7, 8, and 9. Those pairs were suffixed '.1' and '.2'; for example, LG01.1 and LG01.2 (Table 2, Figure 1, Additional file 6). In HG2, three linkage groups were identified and designated as LG02.1, LG02.2, and LG02.3. Because two remaining linkage groups were generated with some common markers from previously reported maps, these linkage groups were tentatively named LG10.1(t) and LG10.2(t).

The average marker density of the SKF2 maps was $1.9 \mathrm{cM}$ in total, ranging from $1.1 \mathrm{cM}$ for LG01.2 to $11.4 \mathrm{cM}$ for LG10.1(t) in the 21 linkage groups. The largest interval between two loci was $25.6 \mathrm{cM}$, observed between AHGS1270 and AHGS1947 on LG08.1. In the SKF2 map, $28.3 \%$ of the total marker loci showed 
Table 2 Length, number of mapped marker loci, and segregation distortion of the linkage maps

\begin{tabular}{|c|c|c|c|c|c|c|c|c|c|c|c|c|c|c|}
\hline \multirow{2}{*}{$\begin{array}{l}\text { Linkage } \\
\text { group }\end{array}$} & \multicolumn{7}{|l|}{ SKF2 } & \multicolumn{7}{|l|}{ NYF2 } \\
\hline & \multirow{2}{*}{$\begin{array}{l}\text { Length } \\
\text { (cM) }\end{array}$} & \multicolumn{4}{|c|}{$\begin{array}{l}\text { Number of } \\
\text { marker loci }\end{array}$} & \multirow{2}{*}{$\begin{array}{l}\text { Marker } \\
\text { density }\end{array}$} & \multirow{2}{*}{$\begin{array}{l}\text { Segregation } \\
\text { distortion } \\
\text { ratio }^{\text {a) }} \\
(\%)\end{array}$} & \multirow{2}{*}{$\begin{array}{l}\text { Length } \\
\text { (cM) }\end{array}$} & \multicolumn{4}{|c|}{$\begin{array}{l}\text { Number of } \\
\text { marker loci }\end{array}$} & \multirow{2}{*}{$\begin{array}{l}\begin{array}{l}\text { Marker } \\
\text { density }\end{array} \\
\text { (cM/loci) }\end{array}$} & \multirow{2}{*}{$\begin{array}{l}\text { Segregation } \\
\text { distortion } \\
\text { ratio }^{\text {a) }}\end{array}$} \\
\hline & & Total & AHGS & $A h T E^{b)}$ & Published $^{c)}$ & & & & Total & AHGS & AhTE $^{\text {b) }}$ & Published $^{c)}$ & & \\
\hline LG01.1 & 126.9 & 59 & 29 & 23 & 7 & 2.2 & 28.8 & 74.7 & 46 & 28 & 13 & 5 & 1.7 & 4.3 \\
\hline LG01.2 & 60.9 & 61 & 34 & 19 & 8 & 1.0 & 19.7 & 56.9 & 13 & 10 & 3 & 0 & 4.7 & 15.4 \\
\hline LG02.1 & 101.3 & 69 & 36 & 20 & 13 & 1.5 & 18.8 & 66.6 & 30 & 22 & 7 & 1 & 2.3 & 3.3 \\
\hline $\mathrm{LG02.2}$ & 94.7 & 66 & 34 & 18 & 14 & 1.5 & 28.8 & 4.9 & 2 & 2 & 0 & 0 & 4.9 & 50.0 \\
\hline LG02.3 & 44.1 & 24 & 14 & 3 & 7 & 1.9 & 16.7 & 21.1 & 5 & 3 & 1 & 1 & 5.3 & 0.0 \\
\hline LG03.1 & 117.0 & 78 & 42 & 26 & 10 & 1.5 & 39.7 & 97.2 & 31 & 19 & 9 & 3 & 3.2 & 0.0 \\
\hline LG03.2 & 101.7 & 55 & 32 & 14 & 9 & 1.9 & 16.4 & 76.0 & 9 & 6 & 1 & 2 & 9.5 & 0.0 \\
\hline LG04.1 & 125.6 & 87 & 34 & 37 & 16 & 1.5 & 31.0 & 104.3 & 13 & 6 & 7 & 0 & 8.7 & 23.1 \\
\hline$\overline{L G 04.2}$ & 103.5 & 40 & 29 & 7 & 4 & 2.7 & 32.5 & 106.6 & 15 & 7 & 7 & 1 & 7.6 & 20.0 \\
\hline LG05.1 & 112.2 & 43 & 21 & 18 & 4 & 2.7 & 9.3 & 62.4 & 6 & 4 & 2 & 0 & 12.5 & 33.3 \\
\hline LG05.2 & 98.3 & 60 & 37 & 16 & 7 & 1.7 & 23.3 & 84.2 & 8 & 1 & 7 & 0 & 12.0 & 0.0 \\
\hline LG06.1 & 114.0 & 42 & 27 & 12 & 3 & 2.8 & 38.1 & - & - & - & - & - & - & - \\
\hline LG06.2 & 91.7 & 56 & 25 & 24 & 7 & 1.7 & 19.6 & 146.5 & 44 & 21 & 17 & 6 & 3.4 & 9.1 \\
\hline LG07.1 & 160.9 & 55 & 38 & 9 & 8 & 3.0 & 29.1 & 167.3 & 44 & 29 & 10 & 5 & 3.9 & 6.8 \\
\hline LG07.2 & 146.3 & 62 & 26 & 21 & 15 & 2.4 & 43.5 & 2.9 & 2 & 1 & 1 & 0 & 2.9 & 0.0 \\
\hline$\overline{L G 08.1}$ & 199.8 & 38 & 17 & 15 & 6 & 5.4 & 15.8 & 98.5 & 24 & 8 & 12 & 4 & 4.3 & 4.2 \\
\hline LG08.2 & 91.8 & 68 & 38 & 20 & 10 & 1.4 & 57.4 & 49.4 & 15 & 10 & 4 & 1 & 3.5 & 13.3 \\
\hline LG09.1 & 112.6 & 81 & 48 & 27 & 6 & 1.4 & 19.8 & 72.8 & 7 & 2 & 4 & 1 & 12.1 & 14.3 \\
\hline LG09.2 & 83.1 & 50 & 25 & 15 & 10 & 1.7 & 22.0 & 16.7 & 10 & 5 & 2 & 3 & 1.9 & 0.0 \\
\hline LG10.1(t) & 79.9 & 8 & 5 & 2 & 1 & 11.4 & 37.5 & - & - & - & - & - & - & - \\
\hline LG10.2(t) & 59.3 & 12 & 7 & 5 & 0 & 5.4 & 8.3 & - & - & - & - & - & - & - \\
\hline$\overline{L G X}$ & - & - & - & - & - & - & - & 23.9 & 2 & 2 & 0 & 0 & 23.9 & 0.0 \\
\hline Total & 2166.4 & 1114 & 598 & 351 & 165 & 1.9 & 27.7 & 1332.9 & 326 & 186 & 107 & 33 & 4.3 & 7.7 \\
\hline
\end{tabular}

a) Percentages of segregation loci with probability level $\mathrm{P}<0.05$.

b) Including the AhTE markers developed in the previous study (Shirasawa et al. 2012).

c) Including the BAC-end SSR markers developed by Bertioli et al. (unpublished).

segregation distortions, ranging from $42.2 \%$ in LG07.2 to $8.3 \%$ in LG10.2(t) (Table 2, Additional file 6).

\section{Construction of the NYF2 linkage map}

A total of 338 of the 7,151 (4.7\%) tested markers showed polymorphism between 'Nakateyutaka' and 'YI-0311'. While four markers identified double polymorphic loci, the other 334 markers generated single polymorphic loci. Consequently, 342 polymorphic loci were generated from the 338 markers. Because the SNP for the D150N change in ahFAD2A [56,57] and the transposon insertion polymorphism at the $665^{\text {th }}$ base in $a h F A D 2 B$ [49] segregated in the NYF2 population, the ahFAD2A and ahFAD2B genes were subjected to genotyping of the $F_{2}$ population together with the 342 polymorphic loci. A total of 326 segregating loci (94.8\%) formed 19 linkage groups (LGs) (Table 2, Additional file 6, Additional file 8). Of the 19 LGs, 18 were numbered corresponding to the SKF2 maps and the previously reported maps with 18 anchor markers [19,22,23,25,27,28,30] (Additional file 7, Additional file 8 ). The remaining linkage group was tentatively named LGX because this LG had the possibility of corresponding to either LG06.1, LG10.1(t), or LG10.2(t) of the SKF2. The ahFAD2A and $a h F A D 2 B$ genes were mapped onto LG9.2 and LG9.1, respectively, as reported by Qin et al. [30]. The total length of the map was 1,332.9 cM, with individual LGs ranging from $2.9 \mathrm{cM}$ (LG07.2) to $167.3 \mathrm{cM}$ (LG07.1). The average marker density was $4.3 \mathrm{cM}$, ranging from $1.7 \mathrm{cM}$ in the LG01.1 to $23.9 \mathrm{cM}$ in the LGX. In the NYF2 map, $7.7 \%$ of the marker loci showed significant segregation distortions. The highest segregation distortion was observed in LG2.2 (50\%), whereas seven LGs had no distorted loci (Table 2, Additional file 6). Of the 326 loci, 293 were generated from markers developed in this study and in Shirasawa et al. [34]. 


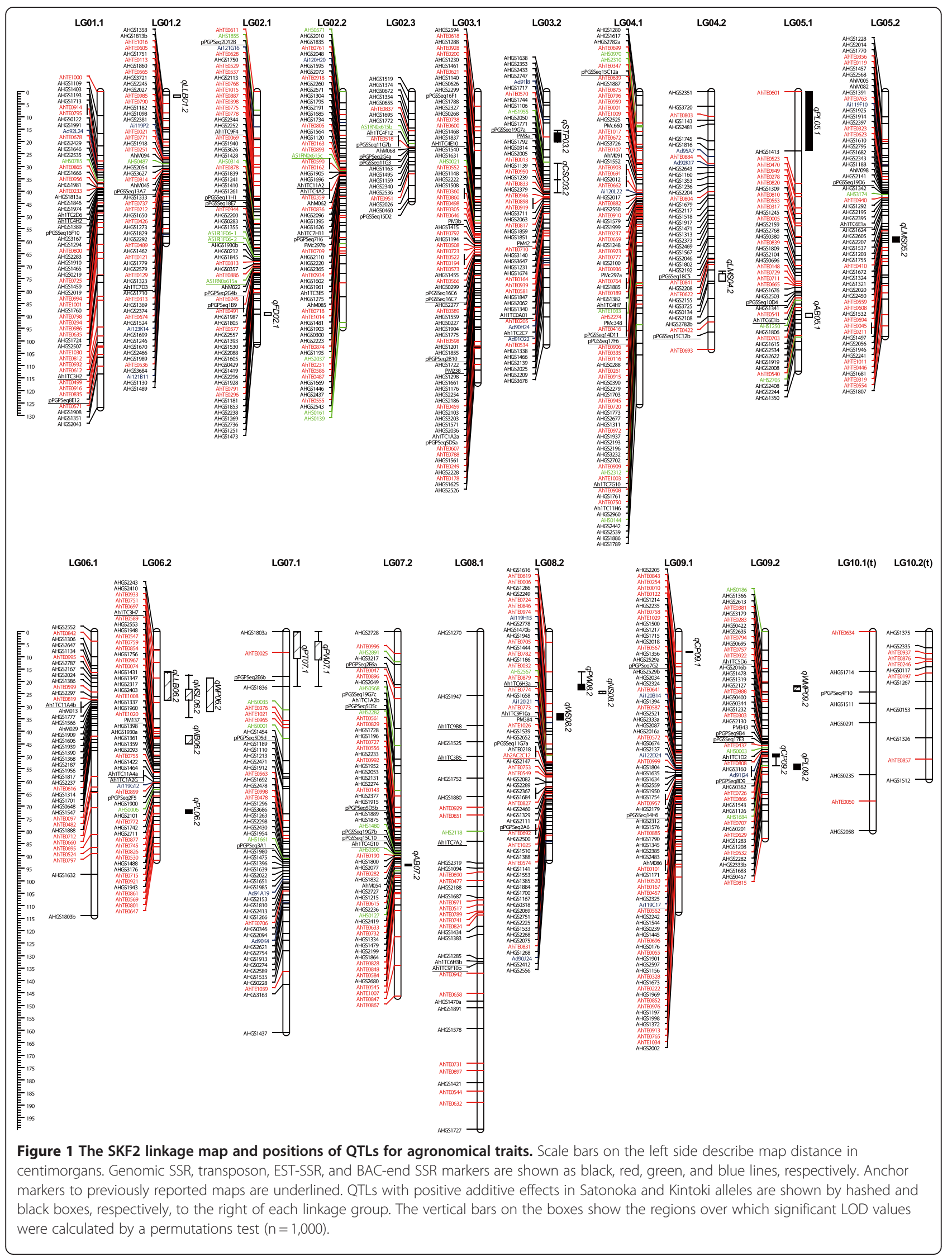




\section{Detection of QTLs for agronomical traits}

Phenotypic values of 15 morphological quantitative traits investigated in SKF2 exhibited transgressive segregation relative to the mapping parents (Additional file 9). A total of 23 significant QTLs were detected for the 15 investigated traits (Table 3, Figure 1). The phenotype variance explained by the QTLs ranged from 4.8 to $28.2 \%$. A QTL for flowering date was detected on LG02.1 and named as qFD02.1, of which the 'Kinotki' allele had an effect of late flowering. Two QTLs for branching angle, qAB05.1 and $q A B 07.2$, were detected on LG05.1 and LG07.2, with opposite directions of additive effects. As traits for plant size, three (qLMS06.2, qLMS04.2, and qLMS05.2), two ( $q L L B 06.2$ and $q L L B 01.2)$, one (qNB06.2), and one (qWP06.2) QTLs affecting the length of the main stem, length of the longest branch, number of branches, and weight of the plant were detected, respectively, all of which had positive additive effects for the 'Kintoki' allele except for qLMS05.2. QTLs for length of the main stem, length of the longest branch, and weight per plant were detected in the same marker interval in LG06.2. The traits showed significant correlation with each other, and therefore it was suggested that the identified QTLs controlled plant biomass (Additional file 10). For pod characters, three QTLs for length (qPL05.1, qPL09.2, and qPL06.2), one for thickness ( $q P$ T07.1), two for wideness ( $q$ PW07.1 and $q P W 08.2)$, two for constriction $(q C P 09.2$ and $q$ CP09.1), and one for shape of the beak (qSTP03.2) were detected. QTLs for seed weight ( $q$ WSO8.2) and number of seeds per plant (qNS08.2) did not overlap but did map to the same LG (LG08.2). A QTL cluster was found for pod thickness and width on LG07.1, and the correlation was significant (Additional file 10). Thus, the QTL was considered to regulate lateral growth of pods. Other QTLs related to pod character, i.e., weight of mature pod per plant ( $q$ WMP09.2), length of pod ( $q$ PL09.2), and constriction of pod ( $q C P 09.2)$, mapped on LG09.2 but in different marker intervals. The trait for red seed coat color ( $q C S C 03.2)$, which is not a quantitative but a qualitative trait, segregated into 77 red and 17 orange-yellow

Table 3 Positions, effects, and phenotypic variation explained by QTLs for 15 agronomic traits detected in the SKF2 population

\begin{tabular}{|c|c|c|c|c|c|c|c|}
\hline Trait & $\begin{array}{l}\text { QTL } \\
\text { name }\end{array}$ & $\begin{array}{l}\text { Linkage } \\
\text { group }\end{array}$ & Marker interval & LOD & $\begin{array}{l}\text { Additive } \\
\text { effect }^{\mathrm{a})}\end{array}$ & $\begin{array}{l}\text { Dominant } \\
\text { effect }^{\text {a) }}\end{array}$ & $\begin{array}{l}\text { Phenotypic } \\
\text { variation } \\
\text { explained (\%) }\end{array}$ \\
\hline Flowering date (day) & qFD02.1 & LG02.1 & AHGS2736-AHGS1251 & 5.0 & 1.7 & -2.4 & 19.5 \\
\hline \multirow[t]{2}{*}{ Angle of branch (1: erect to 5: spread-out) } & $q A B 05.1$ & LG05.1 & AHGS2534-AHGS2622 & 5.7 & 0.5 & -0.9 & 11.9 \\
\hline & $q A B 07.2$ & LG07.2 & AHGS1215-AhTE0615 & 4.6 & -0.6 & 0.2 & 23.2 \\
\hline \multirow[t]{3}{*}{ Length of main stem $(\mathrm{cm})$} & qLMS06.2 & LG06.2 & AhTE0589-Ah1TC3H7 & 7.9 & 2.8 & 7.2 & 4.8 \\
\hline & qLMS04.2 & LG04.2 & AHGS2155-AHGS3725 & 6.8 & 4.5 & 2.3 & 19.2 \\
\hline & qLMS05.2 & LG05.2 & AHGS2020-AHGS2450 & 4.6 & -4.4 & 2.0 & 15.7 \\
\hline \multirow[t]{2}{*}{ Length of the longest branch $(\mathrm{cm})$} & qLLB06.2 & LG06.2 & AhTE0697-Ah1TC3H7 & 5.7 & 7.6 & 9.9 & 21.1 \\
\hline & qLLB01.2 & LG01.2 & $\begin{array}{l}\text { AHGS1813b- } \\
\text { AhTE1016 }\end{array}$ & 4.7 & 4.9 & -7.0 & 14.2 \\
\hline Number of branches (branch) & qNB06.2 & LG06.2 & AhTE0967-AhTE0074 & 5.1 & 5.2 & 3.8 & 15.6 \\
\hline Weight of plant (g) & qWP06.2 & LG06.2 & AhTE0697-Ah1TC3H7 & 5.4 & 7.8 & 12.9 & 11.8 \\
\hline Weight of mature pod per a plant (g) & qWMP09.2 & LG09.2 & AHGS0422-AHGS2635 & 7.2 & 5.4 & 2.2 & 28.1 \\
\hline \multirow[t]{3}{*}{ Length of pod (mm) } & qPL05.1 & LG05.1 & AhTE0601-AHGS1413 & 6.7 & -2.4 & 2.2 & 28.2 \\
\hline & qPL09.2 & LG09.2 & AHS1684-AhTE0707 & 5.4 & -1.5 & -1.6 & 8.4 \\
\hline & qPL06.2 & LG06.2 & AhTE0745-AhTE0826 & 4.9 & -2.1 & 1.1 & 20.5 \\
\hline Thickness of pod (mm) & qPT07.1 & LG07.1 & AHGS1803a-AhTE0025 & 11.9 & 1.0 & 0.4 & 21.7 \\
\hline \multirow[t]{2}{*}{ Width of pod (mm) } & qPW07.1 & LG07.1 & $\begin{array}{l}\text { AhTE0025- } \\
\text { pPGPSeq2E6b }\end{array}$ & 11.4 & 0.6 & 0.4 & 15.2 \\
\hline & qPW08.2 & LG08.2 & AHGS1286-AHGS2249 & 9.5 & -0.7 & 0.4 & 25.5 \\
\hline \multirow[t]{2}{*}{ Constriction of pod (1: deep to 5: shallow) } & qCP09.2 & LG09.2 & AHGS0362-AhTE0726 & 8.1 & -0.6 & -0.5 & 18.1 \\
\hline & qCP09.1 & LG09.1 & AHGS1673-AhTE0222 & 6.2 & 0.3 & 0.6 & 6.9 \\
\hline Shape of tip of pods (1: round to 5 : sharp) & qSTP03.2 & LG03.2 & AhTE0570-AHGS1744 & 5.9 & -0.3 & 0.7 & 9.9 \\
\hline Weight of a seed (g) & qWS08.2 & LG08.2 & AhTE0846-AhTE0974 & 4.9 & -0.1 & 0.1 & 19.1 \\
\hline Number of seeds per a plant (grain) & qNS08.2 & LG08.2 & AHGS1286-AHGS2249 & 5.2 & 3.0 & 28.3 & 6.8 \\
\hline $\begin{array}{l}\text { Color of seed coat (2: orange-yellow to } 5 \text { : } \\
\text { brown-red) }\end{array}$ & qCSC03.2 & LG03.2 & PM3a-AHGS1792 & 67.4 & 0.6 & 1.4 & 9.7 \\
\hline
\end{tabular}

a) Effect of 'Kintoki' allele. 
offspring, fitting a 3:1 ratio by the chi-square test $\left(x^{2}=0.12, p=0.73\right)$. This trait mapped to a single locus between two marker loci, PM3a and AHGS1792, in the LG03.2 with an LOD value of 67.4.

\section{Relationship between mutations of ahFAD2 genes and the $\mathrm{O} / \mathrm{L}$ ratio}

In NYF2, fatty acid concentration was determined for the parental and 185 individual $\mathrm{F}_{2}$ seeds. The $\mathrm{O} / \mathrm{L}$ ratio of the parental lines, 'Nakateyutaka' and 'YI-0311', were $0.98 \pm 0.11$ and $49.4 \pm 4.9$, respectively. The $\mathrm{O} / \mathrm{L}$ ratio of the $\mathrm{F}_{2}$ lines ranged from 0 to 35.2 . Of the $185 \mathrm{~F}_{2}$ plants, the $\mathrm{O} / \mathrm{L}$ ratios of the 178 lines were as low as that of the 'Nakateyutaka', while the other seven were, remarkably, as high as that of 'YI-0311'. The O/L ratio did not significantly correlate with the sum of oleic-acid and linoleic-acid contents, or oleicacid content, but showed negative correlation with linoleicacid content (data not shown). This result suggests that a change in the $\mathrm{O} / \mathrm{L}$ ratio could mainly be attributed to linoleic-acid biosynthesis activity. The significant association between $\mathrm{O} / \mathrm{L}$ ratio in seeds and the combination of genotypes of $a h F A D 2 A$ and $a h F A D 2 B$ was confirmed by GMM analysis with $\mathrm{F}$ value $=1,619.7, p<0.01$. The phenotype variance explained by these two genes was $89.7 \%$. All seven of the $\mathrm{F}_{2}$ seeds that showed a high $\mathrm{O} / \mathrm{L}$ ratio exhibited homozygous genotypes derived from 'YI-0311' on the ahFAD2A and ahFAD2 genes (Figure 2).

\section{Discussion}

In this study, we developed a high-density genetic linkage map, SKF2, of a total length of 2,166.4 cM consisting of 1,114 marker loci (Figure 1, Table 2, Additional file 6). Genetic linkage maps in Arachis spp. have been constructed using mapping populations derived from crosses between interspecific diploids [14,19,22,23] or synthetic tetraploids [13,27], as well as cultivated tetraploids [21,24-26]. In addition, the integration of more than two maps by connecting common markers as anchors has been conducted to produce a higher number of marker loci than that on single maps [28-31]. While it is true that map integration is an effective way to increase marker loci on a single map, the development of new markers is still required to saturate linkage maps in peanut. As far as we know, the SKF2 map covering 2,166.4 cM with 1,114 loci is the highest-density genetic linkage map in Arachis, and probably covers a large portion of the peanut genome because the total length of the map is almost equal to those of maps for tetraploids $(2,210 \mathrm{cM}$ with 370 loci [13], 1,844 cM with 298 loci [27], and $1,785 \mathrm{cM}$ with 191 loci [26]), and double those of maps for wild diploids (1,063 cM with 117 loci [14], 1,231 cM with 170 loci [19], and 1,294 cM with 149 loci [23]).

Our results suggested that in silico polymorphism analysis worked effectively for the development of polymorphic SSR

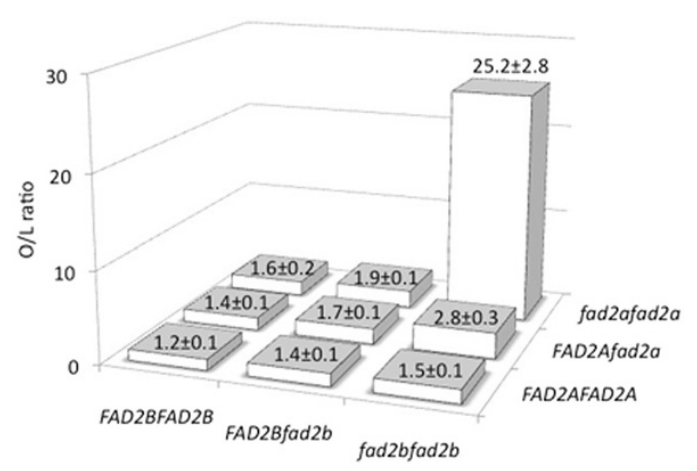

Figure 2 Ratio of oleic-acid to linoleic-acid content (O/L ratio) in peanut seeds of different genotypes of ahFAD2A and ahFAD2B genes in 185 NYF2 plants. Dominant and recessive alleles of FAD2 genes were shown by capital (FAD2A, FAD2B) and lowercase (fad2a, fad2b) letters, respectively. Numeric descriptions are average values for the $\mathrm{O} / \mathrm{L}$ ratio in peanut seeds, with standard errors.

and transposon markers. This was the first time in silico polymorphism analysis has been used in peanut. The polymorphic ratios in SKF2 increased from 15.9\% (=133/838) to $54.4 \%(=331 / 609)$ in total, i.e., $12.6 \%(=42 / 334)$ to $39.2 \%$ $(=29 / 74)$ for genomic SSR markers and $18.1 \%$ (=91/504) to $56.4 \%(=302 / 535)$ for transposon markers, by employing in silico polymorphism analysis. In this study, we performed empirical analysis for 1,833 of 4,019 primer pairs generated via in silico polymorphism analysis. If $32 \%$ of SSR markers derived from a second library show polymorphisms in the SKF2 population, an additional $700[=0.32 \times(4019-1833)]$ markers would map to the SKF2 map.

Though in silico polymorphism analysis was performed for parental lines of SKF2, the analysis increased polymorphic ratios in the NYF2 population as well. This result suggested that in silico polymorphism analysis between two lines enhances the efficiency of polymorphic marker development in this species. Koilkonda et al. [11] investigated genetic distances for 16 Arachis spp. accessions, including the four parental lines used in this study. According to their results, greater genetic diversity was observed among cultivated peanut lines than among our four parental lines. Thus, we considered that marker subsets developed in this study could be useful sources for obtaining polymorphic markers in other mapping populations. However, in parallel, the generation of an insufficient number of polymorphic markers in NYF2 suggested that additional in silico polymorphism analysis is required to develop polymorphic markers that can differentiate between closely-related lines such as the parents of NYF2.

Meanwhile, of the candidate polymorphic sequences, $60.8 \%$ of the SSRs and $43.6 \%$ of the transposon markers did not show polymorphisms. Two reasons might account for 
such identification of false positives in in silico polymorphism analysis. The first is related to the presence of the A and $\mathrm{B}$ genomes in tetraploid peanut. For example, in the case of sequences of one parent being derived from only the A genome and those of another parent being derived from only the B genome, there is a high possibility that homoeologous polymorphisms could be identified but not allelic polymorphisms. Another possible reason is sequencing errors introduced through the use of the Sanger method. New robust sequencing technologies, e.g., pyrosequencing and sequencing by synthesis or ligation, which have been used in massive parallel sequencers, may overcome these two possible causes because the principles underlying the sequencing reaction are different from those of the Sanger method, and duplication ratios of sequences per target region can be increased because of the ability to conduct high-throughput data generation.

The number of linkage groups of the SKF2 was one more than the number of haploid chromosomes of A. hypogaea, and the diversified density of DNA markers on each linkage group ranged from 1.1 to $11.4 \mathrm{cM} /$ marker-locus. This indicates that genetic diversity is different between chromosomes of cultivated peanut. The polymorphism analysis in diploid Arachis species suggested that genetic diversity between $\mathrm{B}$ genome species was considerably lower than that between A genome species [23]. Though we cannot draw any conclusions from this study, it was predicted that similar differences might occur in the tetraploid genome. It has been suggested that the AhMITE1s originated from the $\mathrm{B}$ genome [34] but are currently distributed throughout the whole peanut genome (Figure 1, Table 2, Additional file 6, Additional file 8). This indicates that the AhMITE1s transposed from the $\mathrm{B}$ genome to the combined $\mathrm{A}$ and $\mathrm{B}$ genome without any bias in insertional position.

In the present study, agronomically important traits for flowering date, plant architecture, pod and seed characters, and seed quality were identified. Whereas several QTLs for drought stress tolerance and resistance to rust and foliar diseases have been reported in peanut [24-26,28,31], QTL analyses focused on morphological and physiological traits considered important for breeding have not been conducted. On the other hand, genomic and genetic studies of such traits have progressed in soybean [63-66] and $L$. japonicus [67]; both of these genomes have been sequenced [5,6]. If the genetic knowledge gained through comparative genomics using models is to be applied to crop legumes, the in silico polymorphism analysis must be effective for EST-SSR markers. Because nucleotide sequences of ESTs generally show higher levels of similarity across different species, genera, and families than sequences from intergenic regions, generating and mapping additional EST-SSR markers might help the progress of comparative analysis with other Arachis spp. and model legumes. Further genetic analysis will provide helpful information that will allow the identification of QTLs in peanut corresponding to the genome sequences of model legumes.

Candidate gene approaches, as well as comparative maps, will greatly help to develop DNA markers tightly linked to important traits that have been gained through the study of model legumes. Direct selection of two recessive alleles of the FAD2 genes will facilitate high oleic-acid peanut breeding. Furthermore, introgression breeding of the high-oleic acid trait into elite cultivars can be easily performed with recurrent backcrossings and marker-assisted selection for the sake of monitoring both alleles of the FAD2 genes along with genetic background nature. Similarly, flowering date, pod and seed characters, and plant architecture, as well as stress tolerance and disease resistance, can be efficiently altered by molecular breeding with marker-assisted selection.

\section{Conclusion}

The efficiency of polymorphic marker development was improved remarkably by using in silico polymorphism analysis, in comparison with the previous method, in which primers were simply designed based on the flanking sequences of SSR motifs. The resultant linkage maps possess the highest number of marker loci in cultivated peanut as well as Arachis spp. Moreover, the developed linkage maps are applicable to the identification of QTLs and genes for agronomical traits, including seed quality. These data should be useful for genetics, genomics, and breeding in Arachis spp. This type of in silico polymorphism analysis should also be applicable to other crop species.

\section{Additional files}

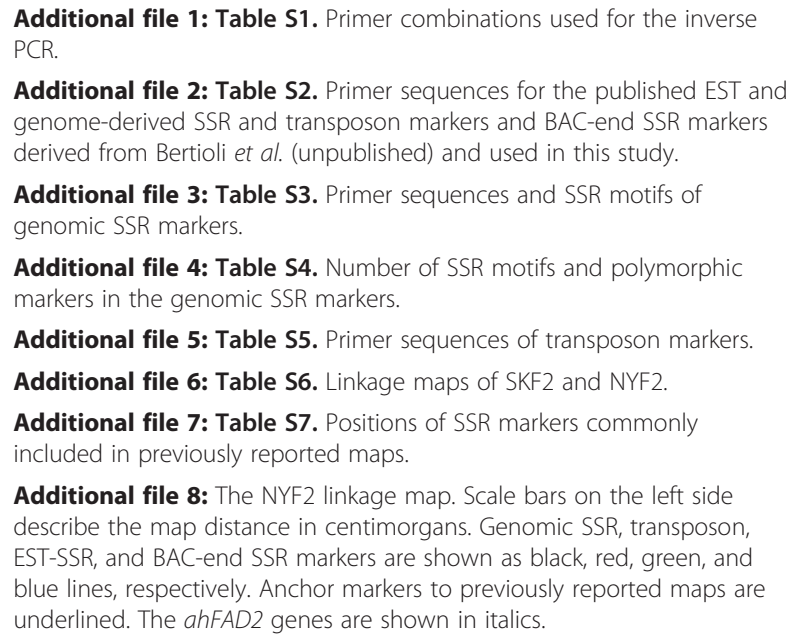

Additional file 1: Table S1. Primer combinations used for the inverse PCR

Additional file 2: Table S2. Primer sequences for the published EST and genome-derived SSR and transposon markers and BAC-end SSR markers derived from Bertioli et al. (unpublished) and used in this study.

Additional file 3: Table S3. Primer sequences and SSR motifs of genomic SSR markers.

Additional file 4: Table S4. Number of SSR motifs and polymorphic markers in the genomic SSR markers.

Additional file 5: Table S5. Primer sequences of transposon markers. Additional file 6: Table S6. Linkage maps of SKF2 and NYF2.

Additional file 7: Table S7. Positions of SSR markers commonly included in previously reported maps.

Additional file 8: The NYF2 linkage map. Scale bars on the left side describe the map distance in centimorgans. Genomic SSR, transposon, EST-SSR, and BAC-end SSR markers are shown as black, red, green, and blue lines, respectively. Anchor markers to previously reported maps are underlined. The ahFAD2 genes are shown in italics.

Additional file 9: Figure S1. Distributions of the investigated traits. Additional file 10: Table S8. Correlation coefficient between quantitative traits. 


\section{Abbreviations}

BAC: Bacterial artificial chromosome; CDNA: Complementary DNA; EST: Expressed sequence tag; GC-TOF-MS: Gas chromatography time-of-flight mass spectrometry; GMM: Genotype Matrix Mapping; HG: Homoeologous linkage groups; LG: Linkage group; LOD: Logarithm of odds; PCR: Polymerase chain reaction; QTL: Quantitative trait locus; SSR: Simple sequence repeat; SNP: Single nucleotide polymorphism.

\section{Acknowledgments}

We are grateful to Dr. Bertioli, University of Brasilia, Brazil, for providing information for SSR markers derived from BAC-end sequences. This work was supported by the foundation of the Kazusa DNA Research Institute.

\section{Author details}

'Kazusa DNA Research Institute, 2-6-7 Kazusa-Kamatari, Kisarazu, Chiba 2920818, Japan. ${ }^{2}$ Chiba Prefectural Agriculture and Forestry Research Center, 808 Daizennocho, Midori, Chiba 266-0006, Japan. ${ }^{3}$ Mitsubishi Chemical Medience Corporation, 4-25-11 Azusawa, Itabashi, Tokyo 174-0051, Japan. ${ }^{4}$ College of Agriculture, Ibaraki University, 3-21-1 Chuo, Ami, Ibaraki 300-0393, Japan. ${ }^{5}$ Center for Transdisciplinary Research, Niigata University, 1-757 Asahimachidori, Chuo, Niigata 951-8585, Japan. ${ }^{6}$ Graduate School of Life \& Environmental Sciences, Osaka Prefecture University, 1-1 Gakuencho, Naka, Sakai, Osaka 599-8531, Japan.

\section{Authors' contributions}

$\mathrm{KS}, \mathrm{Sl}$, and $\mathrm{ST}$ designed this work. CK, HK, MH, and S Suzuki established the mapping populations and performed phenotypic analysis of the plant materials. TK and YN provided their developed SSR markers. AK, AW, CT, HT, KK, KS, M Kato, MW, PK, S Sasamoto, WT, and YK performed the molecular experiments. AN, HH, KA, KS, PK, and SI analyzed the data. $\mathrm{HH}$ and M Kohara constructed the database. KA, KS, and SI wrote the manuscript. All authors read and approved the final manuscript.

Received: 15 February 2012 Accepted: 6 June 2012

Published: 6 June 2012

\section{References}

1. Krapovickas A, Gregory W: Taxonomia del genero Arachis (Leguminosae). Bonplandia 1994, 8:1-186.

2. Krapovickas A, Gregory W: Taxonomy of the genus Arachis (Leguminosae). Bonplandia 2007, 16:1-205.

3. Temsch EM, Greilhuber J: Genome size variation in Arachis hypogaea and A. monticola re-evaluated. Genome 2000, 43:449-451.

4. Bennett MD, Bhandol P, Leitch IJ: Nuclear DNA amounts in angirosperms and their modern uses - 807 new estimates. Ann Bot 2000, 86:859-909.

5. Sato S, Nakamura Y, Kaneko T, Asamizu E, Kato T, Nakao M, Sasamoto S, Watanabe A, Ono A, Kawashima K, Fujishiro T, Katoh M, Kohara M, Kishida Y, Minami C, Nakayama S, Nakazaki N, Shimizu Y, Shinpo S, Takahashi C, Wada T, Yamada M, Ohmido N, Hayashi M, Fukui K, Baba T, Nakamichi T, Mori H, Tabata S: Genome structure of the legume, Lotus japonicus. DNA Res 2008, 15:227-239.

6. Schmutz J, Cannon SB, Schlueter J, Ma J, Mitros T, Nelson W, Hyten DL, Song Q, Thelen JJ, Cheng J, Xu D, Hellsten U, May GD, Yu Y, Sakurai T, Umezawa T, Bhattacharyya MK, Sandhu D, Valliyodan B, Lindquist E, Peto M, Grant D, Shu S, Goodstein D, Barry K, Futrell-Griggs M, Abernathy B, Du J, Tian Z, Zhu L, et al: Genome sequence of the palaeopolyploid soybean. Nature 2010, 463:178-183.

7. Young ND, Debellé F, Oldroyd GE, Geurts R, Cannon SB, Udvardi MK, Benedito VA, Mayer KF, Gouzy J, Schoof H, Van de Peer Y, Proost S, Cook DR, Meyers BC, Spannagl M, Cheung F, De Mita S, Krishnakumar V, Gundlach H, Zhou S, Mudge J, Bharti AK, Murray JD, Naoumkina MA, Rosen B, Silverstein KA, Tang H, Rombauts S, Zhao PX, Zhou P, et al: The Medicago genome provides insight into the evolution of rhizobial symbioses. Nature 2011, 480:520-524.

8. Varshney RK, Chen W, Li Y, Bharti AK, Saxena RK, Schlueter JA, Donoghue MT, Azam S, Fan G, Whaley AM, Farmer AD, Sheridan J, Iwata A, Tuteja R, Penmetsa RV, Wu W, Upadhyaya HD, Yang SP, Shah T, Saxena KB, Michael T, McCombie WR, Yang B, Zhang G, Yang H, Wang J, Spillane C, Cook DR, May $\mathrm{GD}$, Xu X, et al: Draft genome sequence of pigeonpea (Cajanus cajan), an orphan legume crop of resource-poor farmers. Nat Biotechnol 2012, 30:83-89.
9. Udall JA, Wendel JF: Polyploidy and crop improvement. Crop Sci 2006, 46:S3-S14.

10. Hammons RO: The Groundnut Crop: A scientific basis for improvement. In The origin and history of the groundnut. Edited by Smartt J. London: Chapman and Hall; 1994:24-42.

11. Koilkonda P, Sato S, Tabata S, Shirasawa K, Hirakawa H, Sakai H, Sasamoto S, Watanabe A, Wada T, Kishida Y, Tsuruoka H, Fujishiro T, Yamada M, Kohara M, Suzuki S, Hasegawa M, Kiyoshima H, Isobe S: Large-scale development of expressed sequence tag-derived simple sequence repeat markers and diversity analysis in Arachis spp. Mol Breed 2011. doi:10.1007/s11032-0119604-8.

12. Pandey MK, Monyo E, Ozias-Akins $P$, Liang $X$, Guimarães P, Nigam SN, Upadhyaya HD, Janila P, Zhang X, Guo B, Cook DR, Bertioli DJ, Michelmore R, Varshney RK: Advances in Arachis genomics for peanut improvement. Biotechnol Adv 2011, 30:639-651.

13. Burow MD, Simpson CE, Starr JL, Paterson AH: Transmission genetics of chromatin from a synthetic amphidiploid to cultivated peanut (Arachis hypogaea L.): broadening the gene pool of a monophyletic polyploid species. Genetics 2001, 159:823-837.

14. Halward T, Stalker HT, Kochert G: Development of an RFLP linkaeg map in diploid peanut species. Theor Appl Genet 1993, 87:379-384.

15. Proite K, Leal-Bertioli SC, Bertioli DJ, Moretzsohn MC, da Silva FR, Martins NF, Guimarães PM: ESTs from a wild Arachis species for gene discovery and marker development. BMC Plant Biol 2007, 7:7

16. Ferguson ME, Burow MD, Schulze SR, Bramel PJ, Paterson AH, Kresovich S, Mitchell S: Microsatellite identification and characterization in peanut ( $A$. hypogaea L.). Theor Appl Genet 2004, 108:1064-1070.

17. He G, Meng R, Newman M, Gao G, Pittman RN, Prakash CS: Microsatellites as DNA markers in cultivated peanut (Arachis hypogaea L.). BMC Plant Biol 2003, 3:3.

18. Moretzsohn MC, Hopkins MS, Mitchell SE, Kresovich S, Valls JF, Ferreira ME: Genetic diversity of peanut (Arachis hypogaea L.) and its wild relatives based on the analysis of hypervariable regions of the genome. BMC Plant Biol 2004, 4:11.

19. Moretzsohn MC, Leoi L, Proite K, Guimaraes PM, Leal-Bertioli SC, Gimenes MA, Martins WS, Valls JF, Grattapaglia D, Bertioli DJ: A microsatellite-based gene-rich linkage map for the AA genome of Arachis (Fabaceae). Theor Appl Genet 2005, 111:1060-1071.

20. Naito $Y$, Suzuki S, Iwata $Y$, Kuboyama T: Genetic diversity and relationship analysis of peanut germplasm using SSR markers. Breed Sci 2008, 58:293-300.

21. Wang H, Penmetsa RV, Yuan M, Gong L, Zhao Y, Guo B, Farmer AD, Rosen BD, Gao J, Isobe S, Bertioli DJ, Varshney RK, Cook DR, He G: Development and characterization of BAC-end sequence derived SSRs, and their incorporation into a new higher density genetic map for cultivated peanut (Arachis hypogaea L.). BMC Plant Biol 2012, 12:10.

22. Leal-Bertioli SC, Jose AC, Alves-Freitas DM, Moretzsohn MC, Guimaraes PM Nielen S, Vidigal BS, Pereira RW, Pike J, Favero AP, Parniske M, Varshney RK Bertioli DJ: Identification of candidate genome regions controlling disease resistance in Arachis. BMC Plant Biol 2009, 9:112.

23. Moretzsohn MC, Barbosa AV, Alves-Freitas DM, Teixeira C, Leal-Bertioli SC, Guimarães PM, Pereira RW, Lopes CR, Cavallari MM, Valls JF, Bertioli DJ, Gimenes MA: A linkage map for the B-genome of Arachis (Fabaceae) and its synteny to the A-genome. BMC Plant Biol 2009, 9:40.

24. Khedikar YP, Gowda MV, Sarvamangala C, Patgar KV, Upadhyaya HD, Varshney RK: A QTL study on late leaf spot and rust revealed one major QTL for molecular breeding for rust resistance in groundnut (Arachis hypogaea L.). Theor Appl Genet 2010, 121:971-984.

25. Varshney RK, Bertioli DJ, Moretzsohn MC, Vadez V, Krishnamurthy L, Aruna R, Nigam SN, Moss BJ, Seetha K, Ravi K, He G, Knapp SJ, Hoisington DA: The first SSR-based genetic linkage map for cultivated groundnut (Arachis hypogaea L). Theor Appl Genet 2009, 118:729-739.

26. Ravi K, Vadez V, Isobe S, Mir RR, Guo Y, Nigam SN, Gowda MV Radhakrishnan T, Bertioli DJ, Knapp SJ: Varshney RK: Identification of several small main-effect QTLs and a large number of epistatic QTLs for drought tolerance related traits in groundnut (Arachis hypogaea L.). Theor Appl Genet 2011, 122:1119-1132.

27. Foncéka D, Hodo-Abalo T, Rivallan R, Faye I, Sall MN, Ndoye O, Fávero AP, Bertioli DJ, Glaszmann JC, Courtois B, Rami JF: Genetic mapping of wild introgressions into cultivated peanut: a way toward enlarging the genetic basis of a recent allotetraploid. BMC Plant Biol 2009, 9:103. 
28. Gautami B, Pandey MK, Vadez V, Nigam SN, Ratnakumar P, Krishnamurthy L, Radhakrishnan T, Gowda MVC, Narasu ML, Hoisington DA, Knapp SJ, Varshney RK: Quantitative trait locus analysis and construction of consensus genetic map for drought tolerance traits based on three recombinant inbred line populations in cultivated groundnut (Arachis hypogaea L.). Mol Breed 2011. doi:10.1007/s11032-011-9660-0.

29. Hong Y, Chen X, Liang X, Liu H, Zhou G, Li S, Wen S, Holbrook CC, Guo B: A SSR-based composite genetic linkage map for the cultivated peanut (Arachis hypogaea L.) genome. BMC Plant Biol 2010, 10:17.

30. Qin H, Feng S, Chen C, Guo Y, Knapp S, Culbreath A, He G, Wang ML, Zhang X, Holbrook CC, Ozias-Akins P, Guo B: An integrated genetic linkage map of cultivated peanut (Arachis hypogaea L.) constructed from two RIL populations. Theor Appl Genet 2011, 124:653-664.

31. Sujay V, Gowda MVC, Pandey MK, Bhat RS, Khedikar YP, Nadaf HL, Gautami B, Sarvamangala C, Lingaraju S, Radhakrishan T, Knapp SJ, Varshney RK: Quantitative trait locus analysis and construction of consensus genetic map for foliar disease resistance based on two recombinant inbred line populations in cultivated groundnut (Arachis hypogaea L.). Mol Breed 2011. doi:10.1007/s11032-011-9661-z.

32. Tang J, Baldwin SJ, Jacobs JM, Linden CG, Voorrips RE, Leunissen JA, van Eck H, Vosman B: Large-scale identification of polymorphic microsatellites using an in silico approach. BMC Bioinformatics 2008, 9:374.

33. SSRPoly: an efficient tool for polymorphic Simple Sequence Repeat identification. [http://acpfg.imb.uq.edu.au/ssrpoly.php].

34. Shirasawa K, Hirakawa H, Tabata S, Hasegawa M, Kiyoshima H, Suzuki S, Sasamoto S, Watanabe A, Fujishiro T, Isobe S: Characterization of active miniature inverted-repeat transposable elements in the peanut genome. Theor Appl Genet 2012, 124:1429-1438.

35. Pandey MK, Gautami B, Jayakumar T, Sriswathi M, Upadhyaya HD, Gowda MVC, Radhakrishnan T, Bertioli DJ, Knapp SJ, Cook DR, Varshney RK: Highly informative genic and genomic SSR markers to facilitate molecular breeding in cultivated groundnut (Arachis hypogaea). Plant Breed 2012, 131:139-147.

36. Holbrook CC, Stalker HT: Plant Breeding Reviews. Volume 22. In Peanut breeding and genetic resources. Edited by Janick J. New York: John Willey and Sons; 2003:297-356.

37. Moore KM, Knauft DA: The inheritance of high oleic acid in peanut. $J$ Hered 1989, 80:252-253.

38. Norden AJ, Gorbet DW, Knauft DA, Young CT: Variability in oil quality among peanut genotypes in the Florida breeding program. Peanut SCi 1987, 14:7-11.

39. Grundy SM: Comparison of monounsaturated fatty acids and carbohydrates for lowering plasma cholesterol. N Engl J Med 1986, 314:745-748.

40. Clemente TE, Cahoon EB: Soybean oil: genetic approaches for modification of functionality and total content. Plant Physiol 2009 151:1030-1040.

41. Garces R, Mancha M: In vitro oleate desaturase in developing sunflower seeds. Phytochemistry 1991, 30:2127-2130.

42. Lee MS, Guerra DJ: Biochemical characterization of temperature-induced changes in lipid metabolism in a high oleic acid mutant of Brassica rapa. Arch Biochem Biophys 1994, 315:203-211.

43. Martin BA, Rinne RW: A comparison of oleic acid metabolism in the soybean (Glycine max [L.] Merr.) genotypes Williams and A5, a mutant with decreased linoleic acid in the seed. Plant Physiol 1986, 81:41-44.

44. Barkley NA, Chenault KD, Chamberlin C, Wang ML, Pittman RN: Development of a real-time PCR genotyping assay to identify high oleic acid peanuts (Arachis hypogaea L.). Mol Breed 2010, 25:541-548.

45. Bruner $A C$, Jung $S$, Abbott $A G$, Powell $G L$ : The naturally occurring high oleate oil character in some peanut varieties results from reduced oleoyl-PC desaturase activity from mutation of aspartate 150 to asparagine. Crop Sci 2001, 41:522-526.

46. Chu Y, Holbrook C, Ozias-Akins P: Two alleles of ahFAD2B control the high oleic acid trait in cultivated peanut. Crop Sci 2009, 49:2029-2036.

47. López Y, Nadaf HL, Smith OD, Connell JP, Reddy AS, Fritz AK: Isolation and characterization of the $\Delta 12$-fatty acid desaturase in peanut (Arachis hypogaea L.) and search for polymorphisms for the high oleate trait in Spanish market-type lines. Theor App/ Genet 2000, 101:1131-1138.

48. López Y, Nadaf HL, Smith OD, Simpson CE, Fritz AK: Expressed variants of $\Delta^{12}$-fatty acid desaturase for the high oleate trait in spanish market-type peanut lines. Mol Breed 2002, 9:183-190.
49. Patel M, Jung S, Moore K, Powell G, Ainsworth C, Abbott A: High-oleate peanut mutants result from a MITE insertion into the FAD2 gene. Theor Appl Genet 2004, 108:1492-1502.

50. Nunome T, Negoro S, Miyatake K, Yamaguchi H, Fukuoka H: A protocol for the construction of microsatellite enriched genomic library. Plant Mol Biol Rep 2006, 24:305-312.

51. Sraphet S, Boonchanawiwat A, Thanyasiriwat T, Boonseng O, Tabata S, Sasamoto S, Shirasawa K, Isobe S, Lightfoot DA, Tangphatsornruang S, Triwitayakorn K: SSR and EST-SSR-based genetic linkage map of cassava (Manihot esculenta Crantz). Theor Appl Genet 2011, 122:1161-1170.

52. Rice P, Longden I, Bleasby A: EMBOSS: the European Molecular Biology Open Software Suite. Trends Genet 2000, 16:276-277.

53. Huang X, Madan A: CAP3: a DNA sequence assembly program. Genome Res 1999, 9:868-877.

54. Rozen S, Skaletsky H: Primer3 on the WWW for general users and for biologist programmers. Methods Mol Biol 2000, 132:365-386.

55. Guimarães PM, Garsmeur O, Proite K, Leal-Bertioli SC, Seijo G, Chaine C, Bertioli DJ, D'Hont A: BAC libraries construction from the ancestral diploid genomes of the allotetraploid cultivated peanut. BMC Plant Biol 2008, 8:14.

56. Jung S, Powell G, Moore K, Abbott A: The high oleate trait in the cultivated peanut [Arachis hypogaea L]. II. Molecular basis and genetics of the trait. Mol Gen Genet 2000, 263:806-811.

57. Jung S, Swift D, Sengoku E, Patel M, Teule F, Powell G, Moore K, Abbott A: The high oleate trait in the cultivated peanut [Arachis hypogaea L.]. I. Isolation and characterization of two genes encoding microsomal oleoyl-PC desaturases. Mol Gen Genet 2000, 263:796-805.

58. Van Ooijen JW: JoinMap ${ }^{\circledR} 4$, software for the calculation of genetic linkage maps in experimental populations. Wageningen, Netherlands: Kyazma BV; 2006.

59. Voorrips RE: MapChart: software for the graphical presentation of linkage maps and QTLs. J Hered 2002, 93:77-78.

60. Wang S, Basten CJ, Zeng ZB: Windows QTL cartographer 2.5. Raleigh, NC: Department of Sraristics, North Carolina State University:; 2011.

61. Isobe S, Nakaya A, Tabata S: Genotype matrix mapping: searching for quantitative trait loci interactions in genetic variation in complex traits. DNA Res 2007, 14:217-225.

62. Kazusa DNA Marker Database.[http://marker.kazusa.or.jp]

63. Liu B, Watanabe S, Uchiyama T, Kong F, Kanazawa A, Xia Z, Nagamatsu A, Arai M, Yamada T, Kitamura K, Masuta C, Harada K, Abe J: The soybean stem growth habit gene Dt1 is an ortholog of Arabidopsis TERMINAL FLOWER1. Plant Physiol 2010, 153:198-210.

64. Suzuki M, Fujino K, Nakamoto Y, Ishimoto M, Funatsuki H: Fine mapping and development of DNA markers for the $9 P D H 1$ locus associated with pod dehiscence in soybean. Mol Breed 2010, 25:407-418.

65. Watanabe S, Hideshima R, Xia Z, Tsubokura Y, Sato S, Nakamoto Y, Yamanaka N, Takahashi R, Ishimoto M, Anai T, Tabata S, Harada K Map-based cloning of the gene associated with the soybean maturity locus E3. Genetics 2009, 182:1251-1262.

66. Watanabe S, Xia Z, Hideshima R, Tsubokura Y, Sato S, Yamanaka N, Takahash R, Anai T, Tabata S, Kitamura K, Harada K: A map-based cloning strategy employing a residual heterozygous line reveals that the GIGANTEA gene is involved in soybean maturity and flowering. Genetics 2011, 188:395-407.

67. Gondo T, Sato S, Okumura K, Tabata S, Akashi R, Isobe S: Quantitative trait locus analysis of multiple agronomic traits in the model legume Lotus japonicus. Genome 2007, 50:627-637.

doi:10.1186/1471-2229-12-80

Cite this article as: Shirasawa et al: In silico polymorphism analysis for the development of simple sequence repeat and transposon markers and construction of linkage map in cultivated peanut. BMC Plant Biology 2012 12:80. 